\title{
Lower MPV Can Independently Predict Erectile Dysfunction in T2DM
}

\author{
Aml Mohamed Nada*, Dalia Shaheen
}

Faculty of Medicine, Mansoura University, Mansoura, Dakhahlia, Egypt

*Corresponding author: Aml Mohamed Nada, Faculty of Medicine, Mansoura University, Mansoura, Dakhahlia, Egypt, Tel: +966-56-8089574; Email: aml_nadanoha@yahoo.com

Received date: Sep 29, 2018; Accepted date: Oct 16, 2018; Published date: Oct 22, 2018

Citation: Nada AM, Shaheen D (2018) Lower MPV Can Independently Predict Erectile Dysfunction in T2DM. Int J Appl Sci Res Rev Vol.5 No.3:13.

Copyright: (c) 2018 Nada AM, et al. This is an open-access article distributed under the terms of the Creative Commons Attribution License, which permits unrestricted use, distribution, and reproduction in any medium, provided the original author and source are credited.

\section{Abstract}

Objectives: To find out the frequency of erectile dysfunction in diabetic patients and the association between erectile dysfunction and various clinical and laboratory parameters such as diabetic neuropathy, diabetes control, and cardiovascular risk factors.

Subjects and methods: 91 type 2 diabetic patients were screened for erectile dysfunction. Clinical data were collected and included body mass index (BMI, blood pressure (BP, heart rate, duration of diabetes and diabetes complications mainly peripheral diabetic neuropathy (PDN. Laboratory data included testosterone, pituitary gonadotropins, fasting plasma glucose (FPG, HbA1c, complete blood count (CBC, serum creatinine and lipid profile. Associations of testosterone and erectile dysfunction with various clinical and biochemical parameters were studied.

Results: Erectile dysfunction (ED) was present in $56 \%$ of our patients. No significant difference in total testosterone level, LH, FSH or Prolactin level between patients with and those without erectile dysfunction. Patients with peripheral diabetic Neuropathy were significantly at higher risk for erectile dysfunction (ED) [ $p=0.008$ ]. High $\mathrm{HbA1c}$, Low MPV and low $\mathrm{MCH}$ were significant and independent predictors for ED $(p=0.033$, $0.033,0.004$ respectively, $\mathrm{OR}=1.651,5.562,9.524$ respectively). Testosterone level was negatively and significantly associated with $\mathrm{BMI}$, heart rate and RDW ( $p=$ $<0.005,0.047,0.028$ respectively).

Conclusion: Erectile dysfunction is very common among type 2 diabetic patients. It is strongly and directly associated with peripheral diabetic neuropathy (PDN) so, questionnaire and patient examination for PDN and further interrogation of patients complaining of PDN for erectile dysfunction (ED) is of utmost significance. This disorder can be easily predicted by the low MPV and low MCV which are found to be independent predictors in our study population. ED in T2DM is not related to serum testosterone level. Proper control of blood glucose and reaching the target $\mathrm{HbAlc}$ can protect diabetic patients from development of such disorder as $\mathrm{HbA} 1 \mathrm{c}$ is also found to be a significant independent predictor of it.

Keywords: Diabetes; Erectile dysfunction; MPV; $\mathrm{MCH}$; Neuropathy; Testosterone

\section{Introduction}

Erectile dysfunction (ED is a difficulty in achieving and maintaining adequate erection for a satisfactory sexual performance and the stability of this condition more than $25 \%$ of sexual attempts [1]. It is the most common problem, affecting 80 to $85 \%$ of the patients seeking medical help for sexual dysfunction and its prevalence is expected to reach 322 million people worldwide in 2025 [2]. It occurs due to the complicated interaction between neural, vascular, endocrine, medical and pharmacological factors [3]. Most of these causes affect the intrapenile vasculogenic mechanisms, whether arterial or venous. A common finding is a decrease in local nitric oxide, which is considered as the main neurotransmitter involved in initiation of erection. Fibrosis may also be present within the corpora cavernosa, which limits their expandability, prevents the venules from compressing against the tunica albuginea, and thereby allows venous leakage from the penis [4]. There is an increasing evidence identifying ED as an early finding for atherosclerotic cardiovascular disease and its associated stroke and mortality $[1,5]$.

\section{Materials and Methods}

The study was approved by the Research and Ethics Committee of King Fahd Hospital, Asir Province, Saudi Arabia and informed consent was obtained from each participant. Ninety-one male type 2 diabetic patients were recruited from the out-patient endocrinology clinics from January to June, 2018. Patients were excluded if they had been hospitalized for acute illness such as infection or inflammation within the recent month and if they were already receiving testosterone replacement therapy or medication that can affect the blood test results such as iron therapy. Cardiovascular and peripheral 
arterial disease, kidney disease, thyroid or other endocrine disorder, smoking and anemia were also exclusion criteria.

Detailed history and complete physical examination were done for all participants. Data regarding age, duration of diabetes, presence of diabetes complications and medication were collected. Laboratory investigations included complete blood count $(\mathrm{CBC})$, fasting plasma glucose, $\mathrm{HbA1c}$, lipid profile, serum creatinine, prolactin, total testosterone and pituitary gonadotropins (LH, FSH).

Blood pressure and pulse rate were measured using automatic blood pressure (BP) machine after 5 minutes of rest. Body mass index was also calculated using the formula: $\mathrm{BMI}=$ weight $(\mathrm{kg}) /$ height $(\mathrm{m} 2)$. The International Index of Erectile Function (IIEF) was applied for diagnosis of ED [6] and the revised NDS clinical scoring system was used for diagnosis of peripheral diabetic neuropathy (PDN) [7].

After an overnight fasting venous blood samples were taken into tripotassium ethylene diamine tetraacetic acid, using a Roche Minos cell counter and automatic blood counter (Avid CELL-DYN 3500; Abbot Laboratories, Abbot Park, IL, USA) immediately after sample collection for platelet indices, WBC count, and RBC indices. Standardiza-tion, calibration of instrument, and processing of samples were done according to the manufacturer's instructions. Fasting blood glucose was measured using the glucose oxidase method (Spinreact, Girona, Spain). Total $\mathrm{Hb}$ was measured colorimetrically. HbA1c was determined immunoturbidimetrically. The final result was expressed as percent $\mathrm{HbA} 1 \mathrm{c}$ and is calculated from the $\mathrm{HbA1c} /$ $\mathrm{Hb}$ ratio, including a conversion equation to match a HPLC reference method. $\mathrm{HbA} 1 \mathrm{c}(\%)=\mathrm{HbA} 1 \mathrm{c} / \mathrm{Hb}) \times 175.8+1.73$ [8].

Hormonal assay, FSH, LH, prolactin and total testosterone, TSH, FT4, FT3, in serum were determined by electrochemiluminescent immunoassay on a Roche Modular E170 autoanalyser. Total cholesterol, HDL, cholesterol, and TG were measured by BioMerieux Laboratory, Marcy I'Etoile, France; LDL cholesterol was calculated as follows: LDL-C $=\mathrm{TC}-$ $\mathrm{HDL}-\mathrm{C}-\mathrm{TG} / 5$ according to the method used by Friedewald [9]. Creatinine was measured by kinetic colorimetric assay based on the Jaffé method on Cobas c701 (Roche Diagnostics, Mannheim) according to the manufacturer's instructions.

\section{Our laboratory reference ranges}

Testosterone: $6.7-29 \mathrm{nmol} / \mathrm{l}, \mathrm{LH}: 1.5-12.4 \mathrm{~mol} / \mathrm{l}, \mathrm{FSH}$ : 1.5-12.4 nmol/I, prolactin 65.2-539.1 nmol/I. TSH: 0.35-4.9 ulU/ $\mathrm{ml}$, FT4: 7.5-21.1 pmol/l, FT3: 3.8-7.8 pmol/l. FPG $\mathrm{mmol} / \mathrm{l}$, $\mathrm{HbA} 1 \mathrm{c}$ as \% of total hemoglobin. RBC 4.5-6.3 10\%/L, WBC 4-11 $10^{9} / \mathrm{L}, \mathrm{MCH} 26-36 \mathrm{pg}, \mathrm{MCHC} 32-36 \mathrm{gm} / \mathrm{dL}, \mathrm{HCT} 38-52 \%, \mathrm{Hb}$ 14-18 gm/dL, Platelets 140-440 10\%/L, RDW 11-14\%, MPV 7-13 $\mathrm{fL}, \mathrm{TC}$ : 3-5.2 mmol/l, LDL-C: 3-5.2 mmol/l, HDL-C: 1.04-1.55 $\mathrm{mmol} / \mathrm{l}, \mathrm{TG}:$ 0.34-1.95 mmol/l, creatinine 80-115 $\mu \mathrm{mol} / \mathrm{l}$.

\section{Statistical analysis}

Sample size was calculated by PASS software version 11.0.8 Hintze J. PASS 11. NCSS, LLC. Kaysville, Utah, USA. www.ncss.com.). Calculation relied upon a previous study by Ugwu. In this study $\mathrm{HbA1c}$ was $6.8 \pm 0.8$ in those without ED and $8.0 \pm 1.9$ in those with ED. Group sample sizes of 40 patients with ED and 40 without achieve $95 \%$ power to detect a difference of 1.2 between the null hypothesis that both group means are 6.8 and the alternative hypothesis that the mean of group 2 is 8.0 with estimated group standard deviations of 0.8 and 1.9 and with a significance level (alpha of 0.05000 using a two-sided two-sample t-test.

Data were entered and analyzed using SPSS software (version 21. Categorical data were presented as frequencies and percentages while quantitative data were presented as mean \pm SD if normally distributed (Kolmogorov-Smirnov test $p$ $>0.050$ ) or median and interquartile range (IQR) if skewed (Kolmogorov-Smirnov test $p \leq 0.050$ ). Comparing categorical data for two groups was performed by Chi-square test while comparing quantitative data for two groups was performed by Independent-Samples t-test for normally distributed data or Mann-Whitney $U$ test for skewed data. Correlation of a continuous data with binomial data was done by point bi-serial correlation while its correlation with ordinal/continuous data was done by Spearman's correlation. A diagnostic cut off value of a test to discriminate diseased cases from non-diseased cases was evaluated using Receiver Operating Characteristic (ROC) curve analysis. Predictors were initially tested at univariate level then those with rather significant result were entered into a prediction model using binary logistic regression analysis to detect the independent predictors with their odds ratios $(95 \% \mathrm{Cl})$. Results were considered significant if $p$ value < 0.050 and graphs were used when appropriate.

\section{Results}

Fifty-one patients of the study group (56\% of total number of patients) had erectile dysfunction. These were older in age and had more prevalence of peripheral diabetic neuropathy ( $p=0.039,0.008$ respectively). There was a clear trend towards higher HbA1c in ED patients $(p=0.05$. They also had significantly higher hematocrit (HCT [0.034], and on the other hand, they had significantly lower $\mathrm{MCH}$ ( $p=0.036$ and lower MPV $(p=0.017$.

A binomial logistic regression was performed to ascertain the effects of presence of PDN, age (years, $\mathrm{HbA1C}$, low $\mathrm{MCH}$ ( $<34$ versus $\geq 34$, non-low MCV $(\geq 80$ versus $<80$ and low MPV ( $\leq 9.35$ versus $>9.35$ on the likelihood that participants have ED. Cut off values of 34 for $\mathrm{MCH}$ and 80 for MCV were drawn from the normal reference ranges while a cutoff of 9.35 for MPV was drawn from a ROC curve analysis of our data. The diagnostic accuracy of this cutoff value showed $82.4 \%$ sensitivity, 55\% specificity, 70\% PPV and 71\% NPV (AUC=0.707, p value $=0.001$ ) (Figures 1,2).

High $\mathrm{HbA1c}$ proved to be an independent risk factor of erectile dysfunction $(p=0.033)$ meanwhile low MPV and low $\mathrm{MCH}$ were independent predictors for this disorder $(p=0.036$, 0.034 respectively, $\mathrm{OR}=5.562,9.524$ respectively). Peripheral diabetic neuropathy was a significant risk factor for ED $(p=0.009)$ but it did not prove to be an independent predictor.

(Tables 1-4, Figures1-3) 
Testosterone did not correlate with erectile dysfunction and was not significantly different between both groups of patients $(p=0.645,0.642$ respectively). Testosterone correlated positively and significantly with TC, RBC, Hb, HCT, FSH ( $p=$ $0.037,0.043,0.01,0.046,0.045$ respectively). Testosterone correlated negatively with $\mathrm{BMI}$ values and class, pulse rate, serum creatinine, WBC, RDW and platelet count $(p=<0.0005$, $<0.0005,0.047,0.028,0.032,0.028,0.021$ respectively). (Tables 2,5)

Table 1: Clinical data of patients with and without erectile dysfunction.

\begin{tabular}{|c|c|c|c|c|c|}
\hline \multirow[b]{2}{*}{ Variable } & \multicolumn{2}{|l|}{ Group } & \multirow[t]{2}{*}{ P1 } & \multirow[b]{2}{*}{ Crude OR } & \multirow[b]{2}{*}{ P2 } \\
\hline & $\begin{array}{l}\text { With ED } \\
(n=51)\end{array}$ & $\begin{array}{l}\text { Without ED } \\
(n=40)\end{array}$ & & & \\
\hline Age (years) & $60(47-64)$ & $51(42.25-61)$ & ${ }^{*} 0.039$ & 1.038 & 0.060 \\
\hline $\begin{array}{l}\text { BMI class: Count (Percent) } \\
\text { Ideal }\left(18.5-24.9 \mathrm{~kg} / \mathrm{m}^{2}\right) \\
\text { Overweight }\left(25-29.9 \mathrm{~kg} / \mathrm{m}^{2}\right) \\
\text { Class I obesity }\left(30-34.9 \mathrm{~kg} / \mathrm{m}^{2}\right) \\
\text { Class II obesity }\left(35-39.9 \mathrm{~kg} / \mathrm{m}^{2}\right) \\
\text { Class III obesity }\left(>40 \mathrm{~kg} / \mathrm{m}^{2}\right)\end{array}$ & $\begin{array}{l}3(5.9 \%) \\
1529.4 \%) \\
24(47.1 \% \\
7(13.7 \%) \\
2(3.9 \%)\end{array}$ & $\begin{array}{l}3(7.5 \%) \\
9(22.5 \%) \\
16(40 \%) \\
9(22.5 \%) \\
3(7.5 \%)\end{array}$ & $* * 0.689$ & 0.805 & 0.333 \\
\hline $\mathrm{BMI} \mathrm{kg/ \textrm {m } ^ { 2 }}$ & $30.8(28.7-33.9)$ & $31.5(27.9-35.6)$ & ${ }^{*} 0.349$ & 0.975 & 0.574 \\
\hline SBP mmHg & $130(120.5-141)$ & $134(120-140)$ & ${ }^{*} 0.956$ & 0.992 & 0.582 \\
\hline DBP $\mathrm{mmHg}$ & $77(69-80)$ & $78(69-84)$ & ${ }^{*} .421$ & 0.977 & 0.338 \\
\hline Mean BP & $94(88.2-99.8)$ & $93.3(88.3-103.3)$ & ${ }^{*} .548$ & 0.977 & 0.333 \\
\hline Pulse (Mean \pm SD) bpm & $77.8 \pm 9.4$ & $81.3 \pm 10.5$ & ${ }^{* *} 0.098$ & 0.964 & 0.101 \\
\hline $\begin{array}{l}\text { Presence of Diabetic neuropathy } \\
\text { Count (Percent) }\end{array}$ & $38(74.5 \%)$ & $19(47.5 \%)$ & ${ }^{* * *} 0.008$ & 3.231 & 0.009 \\
\hline Duration of DM (years) & $12(6-16)$ & $8(2.5-15)$ & *0.085 & 1.047 & 0.152 \\
\hline
\end{tabular}

Data are presented as Median (IQR) unless otherwise stated. P1 by *Mann-Whitney $\mathrm{U}$ test,

OR=Odds Ratio, BMI: Body mass index, SBP: Systolic blood pressure, DBP: Diastolic blood pressure, BP: Blood pressure.

${ }^{* *}$ Independent Samples t-Test, ${ }^{* * *}$ Chi-Square test and

${ }^{* * * *}$ Fisher's Exact Test. P2 by Binary Logistic Regression.

Table 2: Laboratory variables of patients with and without erectile dysfunction.

\begin{tabular}{|c|c|c|c|c|c|}
\hline \multirow[b]{2}{*}{ Variable } & \multicolumn{2}{|l|}{ Group } & \multirow[t]{2}{*}{ P1 } & \multirow[b]{2}{*}{ Crude OR } & \multirow{3}{*}{$\begin{array}{l}\text { P2 } \\
0.660\end{array}$} \\
\hline & $\begin{array}{l}\text { With ED } \\
(n=51)\end{array}$ & $\begin{array}{l}\text { Without ED } \\
(n=40)\end{array}$ & & & \\
\hline $\begin{array}{l}\text { Serum total testosterone } \\
\mathrm{nmol} / \mathrm{l}\end{array}$ & $11.25(9.2-17.9)$ & $14.1(8.7-16.9)$ & ${ }^{*} 0.642$ & 0.982 & \\
\hline LH nmol/l & $4.06(3.26-5.17)$ & $3.35(2.77-5.27)$ & ${ }^{*} 0.217$ & 0.934 & 0.357 \\
\hline FSH nmol/l & $4.25(3.53-6.65)$ & $5.05(2.95-7.83)$ & ${ }^{*} 0.636$ & 0.911 & 0.219 \\
\hline Prolactin nmol/l & $134.9(121.8-152.9)$ & $136(90.6-154.1)$ & ${ }^{*} 0.301$ & 0.999 & 0.595 \\
\hline TSH ulU/ml & $1.91(1.31-3.21)$ & $2.39(1.72-3.595)$ & ${ }^{*} 0.334$ & 0.840 & 0.331 \\
\hline FT4 pmol/l & $14.9 \pm 3.3$ & $14.6 \pm 2.3$ & $* * 0.741$ & 1.041 & 0.733 \\
\hline FT3 pmol/l & $4.6 \pm 0.66$ & $4.8 \pm 0.47$ & $* 0.536$ & 0.528 & 0.512 \\
\hline FPG mmol/l & $7.6(6.05-11.9)$ & $8.3(6.73-11.0)$ & ${ }^{*} 0.713$ & 1.017 & 0.766 \\
\hline $\mathrm{HbA} 1 \mathrm{C} \%$ & $8.66 \pm 1.4$ & $8.08 \pm 1.3$ & $* * 0.053$ & 1.381 & 0.058 \\
\hline
\end{tabular}




\begin{tabular}{|c|c|c|c|c|c|}
\hline TC mmol/l & $4.12 \pm 1.05$ & $4.17 \pm 1.13$ & ${ }^{* *} 0.816$ & 0.953 & 0.813 \\
\hline LDL-C mmol/l & $2.1(1.6-2.9)$ & $2.2(1.55-3.0)$ & *0.620 & 0.935 & 0.708 \\
\hline HDL-C mmol/l & $1.025(0.89-1.15)$ & $1.04(0.855-1.2)$ & ${ }^{*} 0.833$ & 0.904 & 0.907 \\
\hline TG mmol/l & $1.42(1.06-1.88)$ & $1.48(1.1-1.9)$ & *0.724 & 1.125 & 0.644 \\
\hline $\mathrm{S} \mathrm{cr} \mu \mathrm{mol} / \mathrm{l}$ & $80.5(70-94.25)$ & $78(69-88)$ & ${ }^{*} 0.412$ & 1.005 & 0.578 \\
\hline WBCs 10/L & $7.00(6.35-8.075)$ & $6.3(5.55-7.675)$ & ${ }^{*} 0.143$ & 1.152 & 0.331 \\
\hline RBCs 10/L & $5.62(5.12-6.048)$ & $5.505(5.2-6.3)$ & *0.693 & 0.862 & 0.493 \\
\hline $\mathrm{Hb}$ gm/dL & $15.95(14.4-16.9)$ & $15.65(14.816 .6)$ & *0.767 & 1.103 & 0.442 \\
\hline НCT \% & $47.8(34.2-51.2)$ & $42.1(33.4-46.6)$ & ${ }^{*} 0.034$ & 1.073 & 0.055 \\
\hline $\mathrm{MCV} f \mathrm{~L}$ & $84.3(29.2-88.4)$ & $77.75(31.2-86.7)$ & ${ }^{*} 0.247$ & 1.010 & 0.312 \\
\hline $\mathrm{MCH}$ pg & $29.9(28.6-41.6)$ & $45.3(29.5-48.5)$ & ${ }^{*} 0.036$ & 0.943 & 0.034 \\
\hline $\mathrm{MCHC}$ gm/dL & $33.3(32.6-71.5)$ & $33.8(30.3-79.7)$ & ${ }^{*} 0.935$ & 0.994 & 0.588 \\
\hline RDW \% & $14.05(13.4-14.7)$ & $13.9(13.5-14.6)$ & *0.755 & 1.175 & 0.487 \\
\hline PC 10/L & $212.5 \pm 75.5$ & $210.6 \pm 47$ & ** 0.754 & 1.001 & 0.749 \\
\hline MPV fL & $8.75(8.2-9.3)$ & $9.4(8.6-10.2)$ & ${ }^{*} 0.017$ & 0.543 & 0.036 \\
\hline
\end{tabular}

Data are presented as Median (IQR) unless otherwise stated. P1 by

${ }^{*}$ Mann-Whitney U test, ${ }^{* *}$ Independent Samples t-Test. P2 by Binary Logistic Regression. OR=Odds Ratio.

$\mathrm{LH}$ : luteinizing hormone, FSH: follicle stimulating hormone, TSH: thyroid stimulating hormone, FT4: free tetraiodothyronine, FT3: Triiodothyronine,

FPG: Fasting plasma glucose, HbA1c: glycosylated hemoglobin, LDL-C: low density lipoprotein cholesterol, HDL-c: high density lipoprotein cholesterol, TG: triglycerides, $\mathrm{S} \mathrm{cr}$ : serum creatinine

WBC: White blood cell count, RBC: Red blood cell count, $\mathrm{Hb}$ : hemoglobin, HCT: Hematocrete, MCV: Mean corpuscular volume, $\mathrm{MCH}$ : Mean

corpuscular hemoglobin, MCHC: Mean corpuscular hemoglobin concentration, RDW: Red cell distribution width, PC: platelet count, MPV: Mean platelet volume.

\section{Predictors of the likelihood of occurrence of ED}

Table 3 is showing the difference between those with and without ED as regard to these three parameters. There were two studentized residuals with values of -2.988 and -3.494 standard deviations which were kept in the analysis. The logistic regression model was statistically significant ( $\chi 2$ $(6)=33.553, \quad p<0.0005)$. The model explained $43.4 \%$ (Nagelkerke $\mathrm{R}^{2}$ ) of the variance in ED and correctly classified $72.1 \%$ of cases. Sensitivity and positive predictive value were $75.5 \%$, while specificity and negative predictive value were $67.6 \%$. Of the 6 predictor variables, $\mathrm{HbA1C}, \mathrm{MCH}$ and MPV were statistically significant as shown in Table 4. Patients had 1.65 times higher odds to exhibit ED for every $1 \%$ rise in HbA1C, had 9.5 times higher odds to exhibit ED for those with $\mathrm{MCH}<34$, and had 5.56 times higher odds to exhibit ED for those with MPV $\leq 9.35$.

Table 3: MCV, MCH and MPV in the two study groups.

\begin{tabular}{|c|c|c|c|c|c|c|}
\hline \multirow[b]{2}{*}{ Parameter } & \multicolumn{2}{|l|}{ ED group } & \multirow[t]{2}{*}{$x^{2}$} & \multirow[b]{2}{*}{ P1 } & \multirow{2}{*}{$\begin{array}{l}\text { Crude OR } \\
(95 \% \mathrm{Cl})\end{array}$} & \multirow[b]{2}{*}{ P2 } \\
\hline & $\begin{array}{l}\text { With ED } \\
(n=51)\end{array}$ & $\begin{array}{l}\text { Without ED } \\
(n=40)\end{array}$ & & & & \\
\hline Low MCH pg & $36(70.6 \%)$ & $13(32.5 \%)$ & 13.086 & $<0.0005$ & $\begin{array}{l}4.99 \\
(2-12.2)\end{array}$ & $<0.0005$ \\
\hline Non-low MCV fL & $37(72.5 \%)$ & $20(50 \%)$ & 4.870 & 0.027 & $\begin{array}{l}2.6 \\
(1.1-6.3)\end{array}$ & 0.029 \\
\hline Low MPV fL & $42(82.4 \%)$ & $18(45 \%)$ & 13.925 & $<0.0005$ & $\begin{array}{l}5.7 \\
(2.2-14.8)\end{array}$ & $<0.0005$ \\
\hline
\end{tabular}


Data are presented as count (\%). P1 value by Chi-square. This table is showing that the frequency of low MCH ( $<34)$, $\mathrm{OR}=$ Odds ratio, $\mathrm{Cl}=$ confidence interval. $\mathrm{P} 2$ value by simple non-low MCV $(\geq 80)$ and low MPV ( $\leq 9.35)$ are statistically and logistic regression. significantly higher in those with ED as compared to those without ED.

Table 4: Independent predictors of ED.

\begin{tabular}{|c|c|c|c|c|c|c|c|}
\hline \multirow{2}{*}{ Predictor } & \multirow{2}{*}{ B } & \multirow{2}{*}{ S.E. } & \multirow{2}{*}{ Wald } & \multirow{2}{*}{$P$ value } & \multirow{2}{*}{ OR } & \multicolumn{2}{|c|}{$95 \% \mathrm{Cl}$ for OR } \\
\hline & & & & & & Lower & Upper \\
\hline $\begin{array}{l}\text { PDN } \\
\text { Absent } \\
\text { Present }\end{array}$ & 0.194 & 0.651 & 0.089 & 0.766 & $\begin{array}{l}\mathrm{R} \\
1.214\end{array}$ & 0.339 & 4. 352 \\
\hline $\begin{array}{l}\text { MCV fL } \\
<80 \\
\geq 80\end{array}$ & -0.908 & 0.780 & 1.357 & 0.244 & $\begin{array}{l}R \\
0.403\end{array}$ & 0.087 & 1.858 \\
\hline $\begin{array}{l}\mathrm{MCH} \text { pg } \\
\geq 34 \\
<34\end{array}$ & 2.254 & 0.783 & 8.296 & 0.004 & $\begin{array}{l}R \\
9.524\end{array}$ & 2.055 & 44.146 \\
\hline Age (years) & 0.044 & 0.027 & 2.592 & 0.107 & 1.045 & 0.990 & 1.103 \\
\hline HbA1C (\%) & 0.501 & 0.236 & 4.529 & 0.033 & 1.651 & 1.040 & 2.620 \\
\hline $\begin{array}{l}\text { MPV fL } \\
>9.35 \\
\leq 9.35\end{array}$ & 1.716 & 0.577 & 8.835 & 0.003 & $\begin{array}{l}R \\
5.562\end{array}$ & 1.794 & 17.244 \\
\hline Constant & -8.100 & & & & & & \\
\hline
\end{tabular}

Table 5: Correlation of total serum testosterone with clinical and laboratory variables.

\begin{tabular}{|c|c|c|}
\hline Variable & Correlation coefficient & $\mathbf{P}$ \\
\hline Erectile dysfunction & -0.049 & *0.645 \\
\hline Age (years) & -0.074 & 0.485 \\
\hline BMI class & -0.491 & $<0.0005$ \\
\hline $\mathrm{BMI} \mathrm{kg/ \textrm {m } ^ { 2 }}$ & -0.509 & $<0.0005$ \\
\hline SBP mmHg & 0.125 & 0.250 \\
\hline DBP $\mathrm{mmHg}$ & 0.181 & 0.091 \\
\hline MBP $\mathrm{mmHg}$ & 0.198 & 0.066 \\
\hline Pulse bpm & -0.212 & 0.047 \\
\hline Presence of Diabetic neuropathy & 0.044 & *0.681 \\
\hline Duration of DM (yrs) & 0.028 & 0.793 \\
\hline $\mathrm{FPG} \mathrm{mmol/l}$ & -0.124 & 0.252 \\
\hline $\mathrm{HbA} 1 \mathrm{C} \%$ & -0.047 & 0.665 \\
\hline TC mmol/l & 0.229 & 0.037 \\
\hline LDL-C mmol// & 0.194 & 0.079 \\
\hline HDL-C mmol/l & 0.168 & 0.129 \\
\hline TG mmol/l & -0.097 & 0.381 \\
\hline
\end{tabular}




\begin{tabular}{|c|c|c|}
\hline $\mathrm{S} \mathrm{cr} \mu \mathrm{mol} / \mathrm{l}$ & -0.241 & 0.028 \\
\hline TSH ulU/ml & 0.042 & 0.731 \\
\hline T4 pmol/l & 0.293 & 0.078 \\
\hline T3 pmol/l & -0.058 & 0.825 \\
\hline LH nmol/l & 0.186 & 0.080 \\
\hline $\mathrm{FSH} n m o l / l$ & 0.244 & 0.045 \\
\hline Prolactin $\mathrm{nmol} / \mathrm{l}$ & 0.052 & 0.696 \\
\hline WBC 10/L & -0.288 & 0.032 \\
\hline RBC 10/L & 0.271 & 0.043 \\
\hline $\mathrm{Hb}$ gm/dL & 0.340 & 0.010 \\
\hline HCT \% & 0.270 & 0.046 \\
\hline MCV fL & 0.224 & 0.098 \\
\hline $\mathrm{MCH}$ pg & -0.086 & 0.529 \\
\hline $\mathrm{MCHC}$ gm/dL & -0.223 & 0.098 \\
\hline RDW \% & -0.294 & 0.028 \\
\hline PC 10/L & -0.311 & 0.021 \\
\hline MPV fL & 0.143 & 0.294 \\
\hline
\end{tabular}

p value by Spearman's Correlation and *Point Bi-serial Correlation.

LH: luteinizing hormone, FSH: follicle stimulating hormone, TSH: thyroid stimulating hormone, FT4: free tetraiodothyronine,

FT3: Triiodothyronine, FBG: Fasting blood glucose, HbA1c: glycosylated hemoglobin, LDL-C: low density lipoprotein cholesterol,

HDL-c: high density lipoprotein cholesterol, BUN: Blood urea nitrogen, WBC: White blood cell count, RBC: Red blood cell count,

HCT: Hematocrete, MCV: Mean corpuscular volume, $\mathrm{MCH}$ : Mean corpuscular hemoglobin,

MCHC: Mean corpuscular hemoglobin concentration, RDW: Red cell distribution width, MPV: Mean platelet volume.

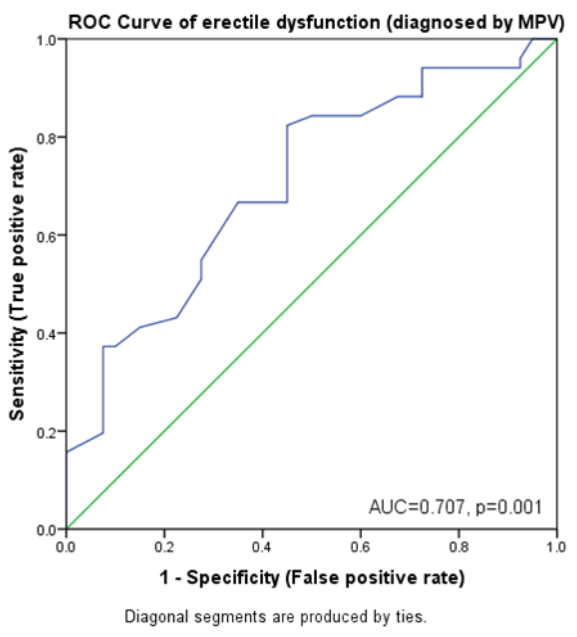

Figure 1: This ROC curve shows that area under the ROC curve (AUC) of diagnosing ED by MPV cutoff value was $0.707(p=0.001)$ 


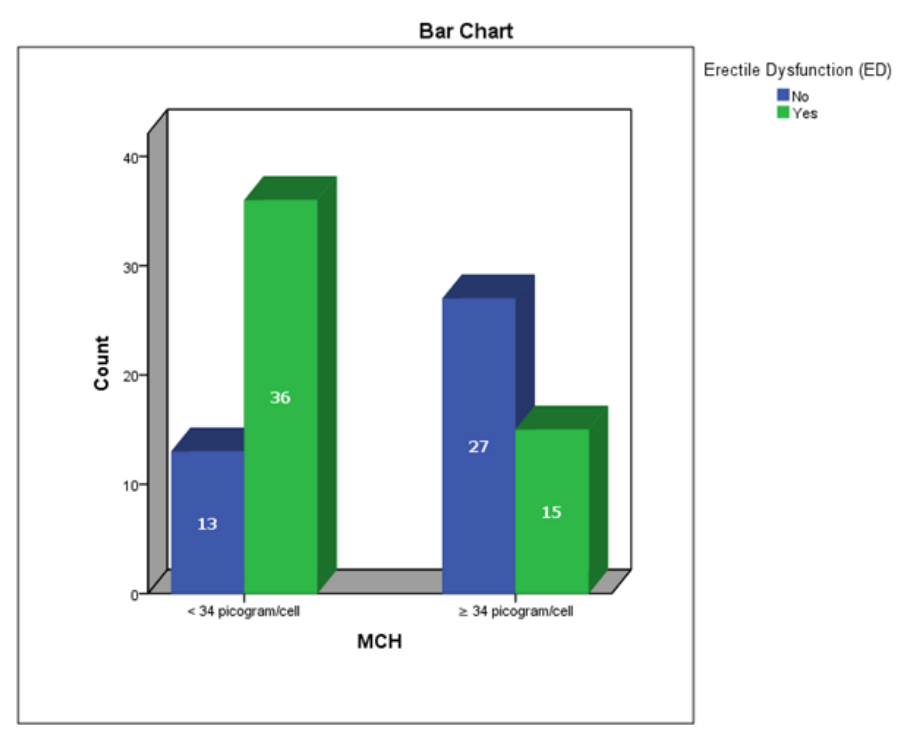

Figure 2: This figure shows that low $\mathrm{MCH}$ is more frequently encountered in those with ED while higher $\mathrm{MCH}$ was more in those without ED

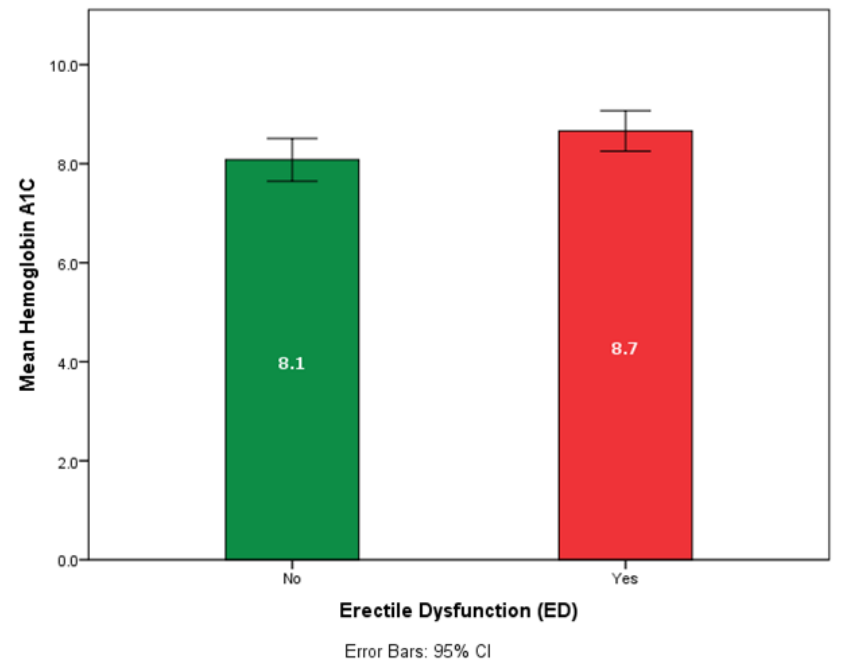

Figure 3: This graph shows that HbA1c is higher in those with ED $(p=0.053)$

\section{Discussion}

Several researchers reported a high prevalence of ED in diabetic patients ranging from 20 to $90 \%$ with more affection at an earlier age than non -diabetic population. The differences in prevalence may be attributed to different criteria of the studied groups [10-12]. For example, in Lal Meena's study the prevalence was $78 \%$ and was associated with higher cardiovascular risk [13] and increased with increasing age. The prevalence increased from
$20 \%$ in the age group less than 40 to $100 \%$ in the age group more than 60 years.

In the Massachusetts male ageing study, men with treated diabetes had a $28 \%$ prevalence of complete ED, about three times higher than the prevalence in the entire study (10\%). It also showed the extremely deleterious epidemiologic link between coronary artery disease, diabetes and ED [14]. In our study, ED was present in $56 \%$ of the study group who were older in age $(p=0.039)$ than those without ED. 
The effect of age on prevalence and severity of the disease might be due to age-related changes occurring in the body and various other complications that may coexist in diabetic patients, but ultimately the accelerated atherosclerosis is the common factor for increased prevalence of ED and cardiovascular disease in aging population [14].

Although Romeo [12] declared peripheral neuropathy as an independent predictor of ED $(p=0.023)$, in our study, diabetic peripheral neuropathy was significantly associated with ED $(p=0.008)$, and it was a significant risk $(0.009)$, however, not an independent predictor.

In a study of 90 patients, Spanish researchers [15] uncovered clear links between erectile dysfunction and peripheral neuropathy. They found strong association between the severity of neuropathy symptoms and ED ( $p=0.009)$.

Similarly, in another study of Japanese, diabetic neuropathy was positively associated with severe erectile dysfunction among diabetic patients aged less than 65 years [16]. In Ugwu's study, autonomic neuropathy was significant only when duration of diabetes was removed from the model [17].

Our patients suffering from ED showed a significant trend towards higher $\mathrm{HbA} 1 \mathrm{c}(\mathrm{p}=0.05)$ and high $\mathrm{HbA1c}$ proved to be an independent predictor of erectile dysfunction $(p=0.033)$. Similar to our observation, $\mathrm{HbA} 1 \mathrm{c}$ was also reported by Romeo and Ugwu and others as an independent predictor of ED in diabetic patients $[12,17]$.

Available studies indicate that increased MPV triggers arterial atherosclerotic processes and thrombosis including penile arteries. Sensitivity of high MPV in detection of arteriogenic ED was mentioned in some reports reaching $54 \%$ with a specificity of $88 \%$ and $82 \%$ positive predictive value $[18,19]$.

In contrast to most literature reports, our study demonstrated statistically significant association of ED with low MPV and accuracy of cut off value $\leq 9.35 \mathrm{fL}$ was shown by an AUC of 0.707 ( $p$ value $=0.001$ ) with sensitivity, specificity, positive predictive value and negative predictive value of $82.4 \%, 55 \%, 70 \%$ and $71 \%$ respectively. Lower MPV had shown to be an independent predictor of erectile dysfunction $(p=0.003, O R=5.562)$.

However, our observation is in agreement with a recent interesting study that was published in 2018, demonstrating the strong association between low MPV and high risk for critical limb ischemia in patients with peripheral arterial atherosclerotic disease. In that study, diabetes was one of the criteria to define critical limb ischemia and ROC analysis revealed a cut-off of $\leq 10.2 \mathrm{fL}$ for MPV to best predict critical limb ischemia (sensitivity: 65\%, specificity: 42\%, positive predictive value: $71 \%$, negative predictive value: $36 \%$ ). MPV was not associated with myocardial infarction or stroke in the same study [20].

Decreased MPV could be regarded as an enhanced consumption of large platelets in inflammatory states [21].
Atherosclerosis affects all vascular beds, so, the earliest symptom development is expected in the artery with the narrowest lumen such as the penile artery. The negative impact of ED on coronary arteries has been published [22].

In our study low $\mathrm{MCH}$ was also an independent predictor of ED $(p=0.004, O R=9.524)$. This is a new observation that is, up to our knowledge, documented for the first time.

In this study, there was no significant difference between both groups of patients in testosterone level indicating that erectile dysfunction in diabetic patient is mostly due to factors other than hypogonadism. Although erections are clearly androgen-dependent, as evidenced by the marked reduction in the frequency, amplitude, and rigidity of erections in marked hypogonadism, the level of androgens required to induce ED is debatable. It is believed that there is a level of testosterone that is required for normal erection in adults and once this threshold is achieved, additional amounts do not further affect the frequency, amplitude, or rigidity of erections [23].

Total testosterone correlated negatively with $\mathrm{BMI}$ value and class in our study population. Similarly, Chuang reported inverse correlation between testosterone level and BMI. It is believed that this inverse correlation is responsible for the modulation of the lean body mass, fat mass and body composition [24].

In agreement with our results is the positive correlation between serum total cholesterol (TC) and testosterone observed by Chuang [24].We did not find significant associations between testosterone and other lipids that may be explained by the fact that most of our patients were receiving hypolipidemic drugs according to the American Diabetes Association clinical practice guidelines 2017.

Al-Chalabi [25] found a significant negative correlation between testosterone and diastolic blood pressure. She also reported a significant negative correlation between testosterone and TC and LDL-C. In our study we did not find such association between testosterone and blood pressure. However, testosterone level correlated negatively with heart rate. The higher the testosterone, the lower the heart rate that may indicate more cardiac fitness and decreased work of the heart. In Poliwczak's study, testosterone therapy reduced heart rate Variability in the treated group of patients [26]

It is noteworthy mentioning that in the present study higher testosterone level was associated with lower serum creatinine level ( $p=0.028$ ). Effect of testosterone on kidney function was previously demonstrated by Goel who reported a significant delay in the progression of chronic kidney disease in patients who received testosterone replacement. The treated men had a $24 \%$ decreased risk of end stage renal disease and $25 \%$ decreased risk of death [27].

Some reports indicate that testosterone increases the biological activity of erythropoietin, alters iron metabolism and stimulates red blood cell production thus increasing 
hemoglobin level [28]. This can explain our observation of the direct and strong correlation between serum testosterone and red cell count, hematocrit and haemoglobin level $(p=0.043$, $0.046,0.01$ respectively).

The relation between atherosclerotic and cardiovascular diseases and white blood cell count was evoked by several authors. Judith [29] demonstrated inverse correlation between total testosterone and total WBC in males 40 to 78 years of age who did not have history of coronary artery disease. We found the same correlation in our study population. These results support a link between hormonal status and low-grade inflammation and consequently the higher risk to atherosclerotic cardiovascular disease.

RDW has shown its significance as a predictive and risk factor for cardiovascular and overall mortality in the general population and in various conditions such as obesity, malignancies, and chronic kidney diseases [30]. In our study it is inversely associated with testosterone level $(p=0.028)$. This may indirectly reflect the link between testosterone level and cardiovascular disease.

\section{Conclusion}

Erectile dysfunction in diabetic patients is strongly associated with peripheral neuropathy, not serum total testosterone level, so sexual history should not be missed in diabetic patients having PDN. This dysfunction can be also easily predicted by the uncontrolled diabetic state and simple $\mathrm{CBC}$. Achieving target $\mathrm{HbA} 1 \mathrm{c}$ in diabetic patients is of utmost significance to avoid ED. Requesting simple inexpensive $C B C$ can significantly reflect the presence of an underlying complication such as ED with its widely known association with coronary atherosclerosis. Erectile dysfunction in diabetic patients is multifactorial as shown by its association with variable clinical and laboratory parameters. We believe that management of diabetes is an art that can has its effect on improving patient's health and quality of life by simple basic and cost-effective clinical practice.

\section{References}

1. Hatzimouratidis K, Amar E, Eardley I, Giuliano F, Hatzichristou D, et al. (2010) Guidelines on male sexual dysfunction: erectile dysfunction and premature ejaculation. Eur Urol 57: 804-814.

2. Ayta IA, McKinlay JB, Krane R (1999) The likely worldwide increase in erectile dysfunction between 1995 and 2025 and some possible policy consequences. BJU International P: 84: 50-56.

3. Ciftci H, Gumus K, Yagmur I, Sahabettin S, Celik H, et al. (2015) Assessment of mean platelet volume in men with vasculogenic and nonvasculogenic erectile dysfunction. Internat J Impotence Res 27: 38-40.

4. American Association of Clinical Endocrinologists Medical Guidelines for Clinical Practice for The Evaluation and Treatment of male Sexual Dysfunction: A Couple's Problem-2003 UPDATE.

5. Dong JY, Zhang YH, Qin LQ (2011) Erectile dysfunction and risk of cardiovascular disease: Meta-analysis of prospective cohort studies. J Amer College of Cardio 58: 1378-1385.
6. Rosen RC, Riley A, Wagner G, Osterloh IH, Kirkpatrick J (1997) The international index of erectile function (IIEF): a multidimensional scale for assessment of erectile dysfunction. Urology 49: 822-830.

7. Meijer JW, Smit AJ, Sonderen EV, Groothoff JW, Eisma WH (2002) Symptom scoring systems to diagnose distal polyneuropathy in diabetes: the Diabetic Neuropathy Symptom score. Diabetic Medicine 19: 962965.

8. European Association for the Study of Diabetes (EASD) News Section 5/2004. Report of the ADA/EASD/IDF Working Group of the HbA1c Assay. London, UK.

9. Friedewald WT, Lvey RI, Fredrickson DS (1972) Estimation of the concentration of low density lipoprotein cholesterol in plasma without the use of the preparative ultracentrifuge. Clin Chem 18: 499-502.

10. Seid A, Gerensea H, Tarko S, Zenebe Y, Mezemir R (2017) Prevalence and determinants of erectile dysfunction among diabetic patients attending in hospitals of central and northwestern zone of Tigray, northern Ethiopia: a crosssectional study. BMC Endocr Disord 17: 16.

11. Kouidrat $\mathrm{Y}$, Pizzol D, Cosco $\mathrm{T}$, Thompson $\mathrm{T}$, Carnaghi $\mathrm{M}$, et al. (2017) High prevalence of erectile dysfunction in diabetes: A systematic review and meta-analysis of 145 studies. Diabet Med 34: 1185-1192.

12. Romeo JH, Seffel AD, Madhum ZT, Aron DC (2000) Sexual function in men with diabetes type 2 association with glycemic control. J Urol 163: 788-791.

13. Lal Meena B, Kochar DK, Agarwal TD (2009) Association between erectile dysfunction and cardiovascular risk in individuals with type-2 diabetes without overt cardiovascular disease. Int J Diabetes Dev Ctries 29: 150-154.

14. Feldman HA, Goldstein I, Hatzichristou DG, Krane RJ, McKinlay JB (1994) Impotence and its medical and psychosocial correlates: Results of the Marsachusetts Male Ageing Study. J Urol 151: 54-61.

15. VallesAntuña C, FernandezGomez J, FernandezGonzalez F (2011) Erectile Dysfunction Study Shows High Prevalence of Peripheral Neuropathy. BJUI 108: 1855-1859.

16. Furukawa S, Sakai T, Niiya T, Miyaoka H, Miyake T, et al. (2017) Diabetic peripheral neuropathy and prevalence of erectile dysfunction in Japanese patients aged $<65$ years with type 2 diabetes mellitus: The Dogo Study. Int J Impot Res 29: 30-34.

17. Ugwu T, Ezeani I, Onung S, Kolawole B, Ikem R (2016) Predictors of Erectile Dysfunction in Men with Type 2 Diabetes Mellitus Referred to a Tertiary Healthcare Centre. Advances in Endocrinology.

18. Sönmez MG, Göğer YE, Sönmez LO, Aydın A, Balasar M, et al. (2017) Can Eosinophil Count, Platelet Count, and Mean Platelet Volume Be a Positive Predictive Factor in Penile Arteriogenic Erectile Dysfunction Etiopathogenesis? Am J Mens Health 11: 678-683.

19. Aldemir M, Akdemir F, Okulu E, Ener K, Ozayar A (2016) Evaluation of blood platelet count and function in patients with erectile dysfunction. Andrologia 48: 189-192.

20. Rief P, Raggam R, Avian A (2018) Low mean platelet volume is associated with critical limb ischemia in peripheral arterial occlusive disease. Scientific Reports. 
21. Gasparyan AY, Ayvazyan L, Mikhailidis DP, Kitas GD (2011). Mean platelet volume: a link between thrombosis and inflammation. Curr Pharm Des p: 47-58.

22. Montorsi P, Montorsi F, Schulman C (2003) Is erectile dysfunction the "tip of the iceberg" of a systemic vascular disorder? Eur Urology 44: 352-354.

23. Jacob Rajfer (2000) Relationship between Testosterone and Erectile Dysfunction. Rev Urol 2: 122-128.

24. Chuang SM, Lee CC, Chien MN, Sun FJ, Wang CH (2016) The Associations between Serum total Testosterone Levels, Anthropometric Measurements and Metabolic Parameters in Elderly and Young Male Patients with Type 2 Diabetes Mellitus in Taiwan. Inter J Gerontology 11: 220-224.

25. Al- Chalabi SS, Al_Waeli AD (2010) The Relatioship Between Serum Testosterone Level, Lipid Profile and Blood Pressure In Infertile Men. Tikrit Medical J 16: 120-123.

26. Poliwczak AR, Tylińska M, Broncel M (2013) Effect of shortterm testosterone replacement therapy on heart rate variability in men with hypoandrogenmetabolic syndrome. Pol Arch Med Wewn 123: 467-73.

27. Goel A, Oni O, Wiegmann P (2017) Testosterone replacement therapy (TRT) delays progression of CKD and ESRD and lower the risk of death in men with hypogonadism. Poster presented at the National Kidney Foundation's 2017 Spring Clinical Meetings in Orlando, Florida.

28. Beggs LA, Yarrow JF, Conover CF, Meuleman JR, Beck DT, et al. (2018) Testosterone alters iron metabolism and stimulates red blood cell production independently of dihydrotestosterone. Aging Male 4: 1-6.

29. Judith SB, Yvonne T, Mitch D (2012) Testosterone, SHBG and differential white blood cell count in middle-aged and older men 71: 274-278.

30. Sahin O, Akpek M, Sarli B, Baktir AO, Savas G, et al. (2015) Association of red blood cell distribution width levels with severity of coronary artery disease in patients with non-ST elevation myocardial infarction. Med Princ Pract 24: 178-183. 